\title{
Expression of c-Kit receptor mRNA and protein in the developing, adult and irradiated rodent testis
}

\author{
Sridurga Mithra Prabhu ${ }^{1}$, Marvin L Meistrich², Eileen A McLaughlin ${ }^{3,4}$, Shaun D Roman ${ }^{3,4}$, \\ Sam Warne ${ }^{1}$, Sirisha Mendis ${ }^{1}$, Catherine Itman ${ }^{1,4}$ and Kate Lakoski Loveland ${ }^{1,4}$ \\ ${ }^{1}$ Centre for Reproduction and Development, Monash Institute of Medical Research, Monash University, Clayton, \\ Victoria 3168, Australia, ${ }^{2}$ Department of Experimental Radiation Oncology, University of Texas M D Anderson \\ Cancer Center, Houston, Texas 77030, USA, ${ }^{3}$ Reproductive Science Group, Discipline of Biological Sciences, \\ University of Newcastle, Callaghan, New South Wales, Australia and ${ }^{4}$ Australian Research Council Centre of \\ Excellence in Biotechnology and Development
}

Correspondence should be addressed to K L Loveland; Email: Kate.loveland@med.monash.edu.au

\begin{abstract}
Germ cell proliferation, migration and survival during all stages of spermatogenesis are affected by stem cell factor signalling through the c-Kit receptor, the expression and function of which are vital for normal male reproductive function. The present study comprehensively describes the $c$-Kit mRNA and protein cellular expression profiles in germ cells of the postnatal and adult rodent testis, revealing their significant elevation in synthesis at the onset of spermatogenesis. Real-time PCR analysis for both mice and rats matched the cellular mRNA expression profile where examined. Localization studies in normal mouse testes indicated that both $c$-Kit mRNA and protein are first detectable in differentiating spermatogonia. In addition, all spermatogonia isolated from 8-day-old mice displayed detectable c-Kit mRNA, but 30-50\% of these lacked protein expression. The $c$-Kit mRNA and protein profile in normal rat testes indicated expression in gonocytes, in addition to differentiating spermatogonia. However, in the irradiated adult rat testes, in which undifferentiated spermatogonia are the only germ cell type, mRNA was also detected in the absence of protein. This persisted at 3 days and 1 and 2 weeks following treatment with gonadotrophin-releasing hormone $(\mathrm{GnRH})$ antagonist to stimulate spermatogenesis recovery. By 4 weeks of $\mathrm{GnRH}$ antagonist treatment, accompanying the emergence of differentiating spermatogonia, both mRNA and protein were detected. Based on these observations, we propose that $c$-Kit mRNA and protein synthesis are regulated separately, possibly by influences linked to testis maturation and circulating hormone levels.

Reproduction (2006) 131 489-499
\end{abstract}

\section{Introduction}

Among the many regulatory factors that tightly control spermatogenesis, the interaction of Kit (known as c-Kit) receptor protein with its ligand, Kitl (also known as Kit ligand and stem cell factor, and referred to here as SCF), plays essential roles, including its specific influence on spermatogonial differentiation and survival at the onset of spermatogenesis (for review see Loveland \& Schlatt 1997, de Rooij \& Grootegoed 1998, Yan et al. 2000). The c-Kit gene encodes a transmembrane tyrosine kinase receptor for the SCF protein. SCF is produced as an integral membrane protein that may be cleaved to release a soluble, extracellular ligand (Loveland \& Schlatt 1997). Expression and functional studies indicate that $c$-Kit is developmentally regulated in male germ cells during both fetal and postnatal development (for review see Mauduit et al. 1999) and localized in Leydig cells in both 6-day postnatal and adult mice (Manova et al. 1990, Rothschild et al. 2003) with the capacity to influence steroidogenesis.

In the mouse, c-Kit mRNA is detected at 7.5-12.0 days postcoitum in primordial germ cells, during their lineage specification and migration to the developing gonadal ridge (Manova \& Bachvarova 1991), and animals with mutations in the genes encoding either SCF or c-Kit exhibit aberrant germ cell migration and proliferation during this period (for review see Mauduit et al. 1999, Zama et al. 2005). The c-Kit mRNA was also detected by in situ hybridization within clones grown in vitro from the germ cells of the newborn mouse testis, which are termed gonocytes, although the functional significance of this observation is uncertain, as no protein expression data were provided (Hasthorpe et al. 1999). In addition, lack of in situ protein expression has been previously reported in gonocytes 
(Yoshinaga et al. 1991). In contrast to the mouse, rat gonocytes have been shown to express both $c$-Kit mRNA and protein (Orth et al. 1996) which was indicated to be required for their normal migration from the centre to the perimeter of the seminiferous cord from day- 1 to day- 5 postpartum in vitro (Orth et al. 1997). Various studies employing in situ hybridization, immunohistochemistry and Northern and Western blotting at time-points concordant with spermatogonial differentiation have reported relatively high levels of $\mathrm{c}$-Kit expression in the cytoplasm of the differentiating spermatogonia and persisting low levels in the meiotic pachytene spermatocytes (Manova et al. 1990, Sorrentino et al. 1991, Dym et al. 1995). The requirement for SCF/C-Kit interactions for progression to and survival in the meiotic pachytene stage of spermatogenesis has also been indicated (Packer et al. 1995, Vincent et al. 1998). However, amongst these studies persist discordant conclusions about the timing and expression pattern of $c$-Kit mRNA and protein at various stages in the juvenile and adult rodent testis, and no single study has addressed this issue in rats and mice simultaneously. An alternative c-Kit transcript, the tr-kit, lacking the extracellular, transmembrane and part of the intracellular kinase domain of the $\mathrm{c}$-Kit receptor protein, is expressed in post-meiotic male germ cells (Albanesi et al. 1996).

More recently, the elevation of c-Kit expression has been linked with the commitment of spermatogonial stem cells to differentiate (Schrans-Stassen et al. 1999). It has also been reported that c-Kit-positive germ cells among the prospermatogonia population of the juvenile testis (termed undifferentiated spermatogonia by SchransStassen et al. 1999) have less repopulating activity than the c-Kit-negative corresponding population (Ohbo et al. 2003). This is in general agreement with studies showing that only c-Kit-negative stem spermatogonia exhibit regenerative activity when transplanted into the adult mouse testis (Shinohara et al. 1999). Thus, knowledge of the timing of $\mathrm{c}$-Kit expression and its regulation is essential for further studies regarding establishment and maintenance of the stem cell population during the first wave of spermatogenesis.

In this study we interrogated the expression profile of c-Kit mRNA and protein in two independent systems, purified spermatogonia derived from 8-day-old mice testes and irradiated adult rat testis. The irradiated testis model provides a powerful avenue for investigating the regulation of c-Kit expression spermatogonia, as irradiation destroys the radiosensitive differentiating spermatogonia, leaving the testis populated only by undifferentiated spermatogonia (Kangasniemi et al. 1996). Gonadotrophinreleasing hormone $(\mathrm{GnRH})$ antagonists stimulate recovery of spermatogenesis when applied at 15 weeks after irradiation and recovery is assessed by scoring the percentage of tubules containing germ cells that have reached the B spermatogonial stage or later, termed the repopulation index. By 4 weeks of treatment, the repopulation index displays a significant increase relative to the 3 -week treatment group, and this index increases steadily in subsequent weeks (Shuttlesworth et al. 2000). In order to examine whether the stimulated recovery of spermatogonial differentiation with $\mathrm{GnRH}$ antagonist treatment is linked to changes in the SCF/C-Kit signalling system, we studied the mRNA and protein expression profiles for $\mathrm{C}-\mathrm{Kit}$ in this model. Surprisingly, in both of these systems we observed that $c$-Kit mRNA could be detected in the absence of protein expression.

This report is the first comprehensive comparison of the timing and expression of $c$-Kit mRNA and protein cellular expression in developing and adult mouse and rat testes. From examination of purified spermatogonial populations and adult irradiated rat testes we have provided evidence that, in purified juvenile mouse germ cells and recovering adult rat testes, $c$-Kit mRNA and protein are differentially regulated in spermatogonia. Our observations are in agreement with previous findings that, based on the age of the postnatal testes, spermatogonial differentiation is indeed concordant with the expression of c-Kit protein.

\section{Materials and Methods}

\section{Animals}

Sprague-Dawley male rats and C57BL and Swiss male mice ranging from juvenile to adulthood were obtained from Monash University Central Animal Services. Swiss mice were also obtained from the University of Newcastle Central Animal Facility. The animals were killed by decapitation (rats and mouse fetuses and juveniles) or cervical dislocation (adult mice) before tissue removal. Tissues were removed immediately after the animals had been killed. Tissue samples for RNA preparation were snap frozen immediately after collection and stored at $-70^{\circ} \mathrm{C}$ until use. Tissue samples for in situ hybridization and immunohistochemistry were placed in Bouin's fixative and processed as described below. All investigations of the developing rat and mouse tissues conformed with the NHMRC/CSIRO/AAC Code of Practice for the Care and Use of Animals for Experimental Purposes and were approved by the Monash University Standing Committee on Ethics in Animal Experimentation and by the University of Newcastle Animal Care and Ethics Committee.

For studies on irradiated testes, adult $\mathrm{LBNF}_{1}$ male rats (hybrids between Lewis and Brown-Norway) were purchased from Harlan Sprague-Dawley, Inc. (Indianapolis, IN, USA). Animals were allowed to acclimatize for 1 week before initiation of the experiment. All procedures were approved by the M D Anderson Cancer Institutional Animal Care and Use Committee.

\section{Irradiation and hormone treatment}

Animals were anaesthetized with $0.72 \mathrm{mg}$ ketamine/kg and $0.022 \mathrm{mg}$ acepromazine/kg (i.m.), and then a single $6 \mathrm{~Gy}$ dose was delivered to the lower part of the abdomen by a 
${ }^{60}$ Co $\gamma$-ray unit (Eldorado 8; Atomic Energy of Canada, Ltd, Ottawa, Canada) as described previously (Shuttlesworth et al. 2000). GnRH antagonist treatment was also performed as previously described (Shuttlesworth et al. 2000). Briefly, 15 weeks after irradiation animals were given simultaneous injections of $1.5 \mathrm{mg}$ Cetrorelix pamoate and $1.5 \mathrm{mg}$ Cetrorelix acetate (ASTA Medica, AG Frankfurt, Germany), each at a different site in the upper portion of the dorsal region. A second dose of Cetrorelix pamoate injection was given 3.3 weeks after the first. This dose continuously suppresses intratesticular testosterone levels by at least $80 \%$ for 5 weeks (Shuttlesworth et al. 2000).

\section{Preparation of testes sections}

Tissue samples for in situ hybridization and immunohistochemistry were placed in Bouin's fixative for $5 \mathrm{~h}$ immediately after collection, then dehydrated through a graded ethanol series and embedded in paraffin. Sections of 3-5 $\mathrm{mm}$ were dried onto Superfrost Plus II slides (MenzelGlaser, Braunswchweig, Germany).

\section{Isolation of spermatogonial fractions}

For isolation of spermatogonia, decapsulated testes from 20-30 8-day postnatal Swiss mice were pooled and incubated for $15 \mathrm{~min}$ each in $0.5 \mathrm{mg} / \mathrm{ml}$ collagenase (Sigma)/ Dulbecco's modified Eagles' medium (DMEM; Invitrogen Australia Pty Ltd, Mount Waverley, Victoria, Australia) with agitation and then in $0.25 \%(\mathrm{v} / \mathrm{v})$ trypsin/EDTA in DMEM. Tubules were dissociated manually by pipetting and washed in $0.5 \%(\mathrm{v} / \mathrm{v})$ bovine serum albumin (BSA) in DMEM by centrifugation. Cell pellets were resuspended in DMEM and filtered twice through a $70 \mu \mathrm{m}$ membrane, then separated over a $2-4 \%$ BSA gradient as described (Baleato et al. 2005). Fractions were collected based on pilot experiments in which labelling with the germ cell marker, GCNA (Wang \& Enders 1996), morphological characteristics and lectin labelling (Arya \& Vanha-Perttula 1986) were used to identify spermatogonia. Cell numbers were quantified (typically $3-6 \times 10^{6} \mathrm{cell} / \mathrm{s} / \mathrm{ml}$ ), and the cells were washed and resuspended in DMEM supplemented with $10 \%(\mathrm{v} / \mathrm{v})$ fetal calf serum (FCS).

Laminin (Sigma; $10 \mu \mathrm{g}$ in $500 \mu \mathrm{l}$ ) in phosphate-buffered saline (PBS) was used to coat the bottom of six-well tissue culture plate wells by overnight incubation at $37^{\circ} \mathrm{C}$. Laminin was removed, the wells were washed three times with $2 \mathrm{ml} \mathrm{PBS}$, and then the dishes were treated with $2 \mathrm{ml}$ $0.5 \mathrm{mg} / \mathrm{ml} \mathrm{BSA}$ in PBS for $1 \mathrm{~h}$ at $37^{\circ} \mathrm{C}$. The wells were then rewashed in PBS three times. Washed, isolated germ cells were resuspended in $2 \mathrm{ml} \mathrm{DMEM} / 10 \%$ (v/v) FCS in wells at a final concentration of $4 \times 10^{5} /$ well and incubated for 1 or $2 \mathrm{~h}$ at $32^{\circ} \mathrm{C}$. Unbound cells were removed and centrifuged at 1500 r.p.m. for $5 \mathrm{~min}$ at $4{ }^{\circ} \mathrm{C}$, washed twice in PBS and then fixed in $4 \%$ paraformaldehyde for $30 \mathrm{~min}$. Cells bound to laminin-coated wells were removed by incubation with $0.25 \%(\mathrm{v} / \mathrm{v})$ trypsin/1 mM EDTA at room temperature for $5 \mathrm{~min}$ followed by vigorous pipetting. Cells were transferred to centrifuge tubes and washed and fixed as described above. Isolated laminin-bound and -unbound spermatogonia were placed onto slides and probed for expression of $c$-Kit mRNA and protein expression.

\section{Quantitative mRNA analysis}

For real-time PCR analysis of each postpartum time-point, total RNA from Swiss mice (two animals pooled per sample, with duplicate samples) and Sprague-Dawley rats (one individual animal per sample, three samples per timepoint) were prepared using the Qiagen RNeasy (Qiagen, Victoria, Australia) following the manufacturer's instructions for mouse samples and the acid-phenol extraction method for rat samples (Chomczynski \& Sacchi 1987) Each total RNA sample was treated with DNA-free (Ambion, Austin, TX, USA) according to the manufacturer's specifications. Five hundred nanograms of this DNA-free total RNA was used for each $20 \mu$ l reverse transcription reaction with $100 \cup$ Superscript III reverse transcriptase (Life Technologies, Grand Island, NY, USA) and oligo-dT primer, according to the enzyme manufacturer's guidelines. Negative control reverse transcription samples were included and these did not have any Superscript III.

PCR samples were prepared in a final volume of $10 \mu \mathrm{l}$ using Roche Diagnostics (Castle Hill, NSW, Australia) SYBR-Green PCR master mix containing $500 \mathrm{nM}$ each forward (F) and reverse (R) primers for mouse (accession number: NM_021099 C-Kit; F, 5'-tcatcgagtgtgatgggaaa-3'; R, 5'-ggtgacttgtttcaggcaca-3') and rat (accession number: NM_022264 C-Kit; F, 5'-ctggtggttcagagtttccatagac-3'; R, 5'-tcaacgaccttcccgaaggcacca- $3^{\prime}$ ) and $1 \mu \mathrm{l}$ reverse-transcribed template. PCR was performed in the LightCycler 2.0 Instrument (Roche Molecular Biochemicals, Mannheim, Germany) using the following light cycler conditions: denaturation $95^{\circ} \mathrm{C}$ for $10 \mathrm{~min}$, amplification $95^{\circ} \mathrm{C}$ for $15 \mathrm{~s}, 60^{\circ} \mathrm{C}$ for $5 \mathrm{~s}, 72^{\circ} \mathrm{C}$ for $10 \mathrm{~s}$ and $72^{\circ} \mathrm{C}$ for $7 \mathrm{~min}$ for 48 cycles. Melting curve analysis and agarose gel electrophoresis were used to monitor accumulation of the PCR products.

The PCR reaction for each sample was performed in duplicate. Negative controls, in which water was used in place of the reverse-transcribed template, were included for each primer pair to detect PCR amplification of any contaminating DNA. The amounts of Actb mRNA (accession number: NM_007393; F, 5'-aggctgtgctgtccctgtat-3'; R, $5^{\prime}$-aaggaaggctggaaaagagc- $3^{\prime}$ ) for the mouse samples and GAPDH mRNA (accession number: BC013852; F, 5'-ttggtatcgtggaaggactca-3'; R, 5'-tgtcatcatatttggcaggttt-3') for the rat samples were measured in each sample template to enable normalization for sample loading of target gene values between samples. The selection of an appropriate housekeeping standard involved comparing abundant mRNAs in the testis over the entire age series. When an analysis of both GAPDH and Actb was performed to validate those genes as standards, they each demonstrated 
constant abundance over the different ages. Actb for the mouse and GAPDH for the rat was chosen to reflect the alignment of their amplification pattern with the number of cycles required for the $c$-Kit cDNA crossing points. To correlate the crossing points from the sample amplification plot with target mRNA copy number, a standard curve was produced for each product in every experiment using cDNA containing the target gene. The data were calculated as the means \pm S.D.

\section{In situ hybridization on tissue sections}

In situ hybridization was used to localize c-Kit mRNAs in mouse and rat testis sections using digoxygenin (DIG)labelled sense and anti-sense c-Kit probes. The probes were initially generated by producing a PCR product from mouse testis cDNA corresponding to base pairs (bp) 89 through 448 of the mouse clone accession number Y00864. The PCR product of $454 \mathrm{bp}$ was cloned into the pGEM T-Easy plasmid (Promega, Madison, WI, USA) following the manufacturer's instructions. The product was verified by sequencing, and it was shown by Northern blot analysis to hybridize to a single band of 5.5 kilobase pairs, as expected for c-Kit mRNA (Qiu et al. 1988, data not shown)

The plasmid containing the $c-$ Kit CDNA fragment was used to produce sense and antisense DIG-cRNAs using SP6 and T7 RNA polymerases in separate reactions containing DIG-UTP (Roche Molecular Biochemicals) and probe labelling was quantified according to the specifications of the DIG-UTP manufacturer. Hybridization was performed using $150 \mathrm{ng} / \mu$ l of each DIG-cRNA, with sections incubated overnight at $55^{\circ} \mathrm{C}$. Washes were performed in decreasing concentrations of SSC (at $2 \times, 1 \times$ and $0.1 \times$ ) at the hybridization temperature. Single strength SSC $(1 \times)$ is $0.15 \mathrm{M}$ sodium chloride and $0.015 \mathrm{M}$ sodium citrate. Treatment with anti-DIG antibody (Roche Molecular Biochemicals; 1:1000 in Roche $1 \times$ blocking solution) and then final development with 5-bromo-4-chloro-3iodylphosphate/nitro blue tetrazolium (BCIP/NBT; Astral Scientific, Sydney, Australia) at room temperature in a light-restricted box was performed to visualize the cell types containing c-Kit mRNA. When sufficient signal had developed, the sections were stained with Harris haematoxylin (Sigma) and mounted in GVA aqueous mounting solution (Zymed Laboratories Inc., San Francisco, USA). Both anti-sense and sense (negative control) cRNAs were used at the same concentration on each sample, in every experiment, for each set of conditions tested.

\section{Immunohistochemistry on tissue sections}

Immunohistochemistry with anti-c-Kit antibodies was undertaken to characterize the cellular c-Kit protein expression profile in tissue sections. Antigen retrieval was performed in $50 \mathrm{mM}$ glycine $\left(\mathrm{pH} 3.5 ;>90^{\circ} \mathrm{C}\right.$ maintained for $8 \mathrm{~min}$ ). For detection of c-Kit protein in rat and mouse testes sections, anti-CD117, a rabbit anti-human antibody
(DAKO, Botany, NSW, Australia; used at $0.5-2.0 \mu \mathrm{g} / \mathrm{ml}$ ) and C-19, a rabbit anti-peptide antibody (Santa Cruz Biotechnology, Santa Cruz, CA, USA, used at $0.1-0.5 \mu \mathrm{g} / \mathrm{ml}$ ) were used as a primary antibodies diluted in $5 \%(\mathrm{v} / \mathrm{v})$ of normal sheep serum in $0.1 \%$ BSA/TBS and sections were incubated overnight at room temperature. Subsequent TBS washes were performed at room temperature between incubations. Primary antibody binding was detected using a biotinylated anti-rabbit antibody (DAKO; biotin anti-rabbit raised in sheep; 1:500 dilution in TBS, $1 \mathrm{~h}$ ) and then the Vectastain Elite $A B C$ kit according to the manufacturer's instructions (Vector Laboratories, Burlingame, CA, USA). Antibody binding was detected as a brown precipitate following development with 3,3'-diaminobenzidine tetrahydrochloride (DAB; Sigma), and Harris haematoxylin was used as the counterstain. The sections were mounted under glass coverslips in Depex (BDH Laboratories, Poole, Dorset, UK).

The two different antibodies used were independently verified by Western blots and recognized proteins of the expected sizes (Nocka et al. 1989, data not shown).

\section{Detection of c-Kit mRNA and protein in isolated spermatogonia}

For detection of mRNA in isolated cell preparations, the $c$-Kit probe was prepared and quantified as described above. Washed spermatogonia were air-dried onto wells in glass slides and then washed $(2 \times 5 \mathrm{~min}$ in PBS, $1 \times 5 \mathrm{~min}$ in PBS/0.02\% (v/v) Triton X-100, $2 \times 5$ min in PBS). Cells were then incubated in proteinase $\mathrm{K}$ for $5 \mathrm{~min}$ at $37^{\circ} \mathrm{C}(5 \mu \mathrm{g}$ proteinase $\mathrm{K} / \mathrm{ml})$ and then incubated in $4 \%(\mathrm{v} / \mathrm{v})$ paraformaldehyde at $4{ }^{\circ} \mathrm{C}$ for $15 \mathrm{~min}$. Cell were washed $(2 \times 5 \mathrm{~min}$ in PBS) and hybridization was performed overnight at $52{ }^{\circ} \mathrm{C}$ (25 ng probe/well) in a humid chamber. Slides were washed ( 5 min in $2 \times \mathrm{SSC} / 50 \%(\mathrm{v} / \mathrm{v})$ formamide) at $55^{\circ} \mathrm{C}$ twice and then $5 \mathrm{~min}$ in $1 \times$ SSC twice. This was followed by treatment as described above with anti-DIG antibody and then final development with BCIP/NBT (Astral Scientific) at room temperature to visualize the cells containing c-Kit mRNA.

For immunohistochemical detection of c-Kit protein, following fixation and washing $(2 \times)$ in PBS/0.02\% (v/v) Triton $\mathrm{X}-100$, spermatogonia were allowed to settle and adhere to 12 -well slides overnight at $4{ }^{\circ} \mathrm{C}$. The slides were washed once in PBS, permeablized with 100\% methanol for $5 \mathrm{~min}$ and washed again in PBS. The slides were blocked using 3\% $(\mathrm{v} / \mathrm{v}) \mathrm{BSA} / \mathrm{PBS}$ for $1 \mathrm{~h}$ at room temperature, then treated with peroxidase $\left(3 \% \mathrm{H}_{2} \mathrm{O}_{2}\right.$ in $\left.\mathrm{PBS}\right)$ for $10 \mathrm{~min}$ at room temperature, washed twice in PBS and incubated with the C-19 primary antibody at 1:100 in 5\% $(\mathrm{v} / \mathrm{v})$ normal rabbit serum in $\mathrm{PBS}$ overnight at $4{ }^{\circ} \mathrm{C}$. The slides were washed twice in PBS, incubated with a secondary antibody labelled with horseradish peroxidase (sheep anti-rabbit; DAKO) at 1:100 for $1 \mathrm{~h}$ at room temperature, and antibody binding wasdetected as a brown precipitate following development with DAB for $5 \mathrm{~min}$, followed by treatment with Harris haematoxylin counterstain. The cells were mounted under glass coverslips in Depex. 


\section{Results}

\section{Expression of c-Kit $m R N A$ and protein in the developing mouse testes}

Quantitative measurements of mRNAs encoding $c$-Kit in mouse (0-, 6-, 10-, 16-, 24- and 42-day) testes were obtained using real-time PCR on total testis RNA samples. The results indicated that day-10 and day-16 time-points had the highest levels of $c$-Kit expression across the ages (Fig. 1A). In situ hybridization analysis of the mouse testis indicated no discernable staining at day 2 (Fig. 1B) and day 5 (data not shown). The $c$-Kit mRNA signal was first
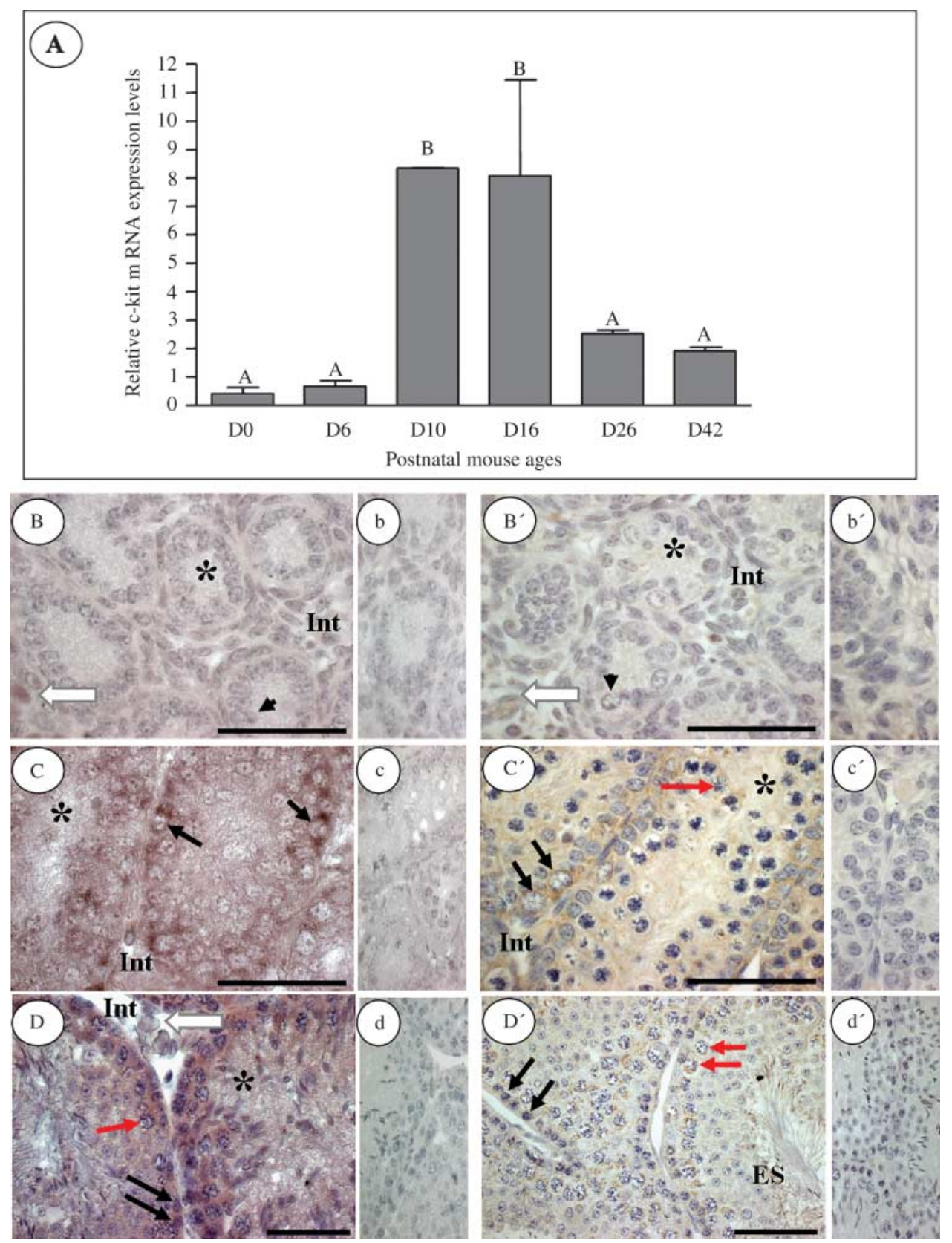

Figure 1 Juvenile and adult mouse testes: $c$-Kit mRNA and protein expression profile. (A) Relative $c$-Kit mRNA expression profile in the mouse testis age series. Data were collected from four animals for each age. The relative $c$-Kit expression was quantified in duplicate for each group using real-time PCR. Results are normalized to $A c t B$ values and presented in relative units of concentration. Error bars represent S.E.M. Different letters above the bars represent the statistical significance between different ages $(P<0.05)\left(D=\right.$ day). (B and $\left.B^{\prime}\right)$ Day-2 mouse testis. $\left(C\right.$ and $\left.C^{\prime}\right)$ Day-10 mouse testis. (D and D') Adult mouse testis. (B, C and D) Anti-sense cRNAs. (b,c and d) Sense cRNA controls. (B', $C^{\prime}$ and D') CD117 anti-c-Kit antibody. ( $b^{\prime}, c^{\prime}$ and $\left.d^{\prime}\right)$ No primary antibody controls. Black arrowheads, gonocyte; thin black arrows, spermatogonium; red arrows, pachytene spermatocyte; asterisks, Sertoli cell cytoplasm; Int, interstitium; ES, elongating spermatid cytoplasm; white arrows, positively stained interstitial cells. Bars equal $50 \mu \mathrm{m}$. 
evident at day 7 in the cytoplasm of some spermatogonia (data not shown). This timing is in accord with the appearance of differentiating spermatogonia (McCarrey 1993). The signals in the day-10 (Fig. 1C) testis samples were confined to the cytoplasm of the differentiating spermatogonia. In addition to differentiating spermatogonia cytoplasmic staining, there was also spermatocyte staining with a relatively lesser intensity and interstitial staining in the adult mouse testis (Fig. 1D).

Immunohistochemistry results identified C-Kit protein in the cell types and time-points at which $c$-Kit mRNA expression was observed in the mouse testis. Protein was not detected within cells of the seminiferous cords at day 2 (Fig. 1B') or at day 5 (data not shown); however, staining was evident in some interstitial cells associated with the persistence of some fetal-type Leydig cells at these ages (Fig. 1B'). Signals were first evident in some spermatogonia in the day-7 testis, consistent with the in situ hybridization results (data not shown), and these were distinct in spermatogonia in the day-10 (Fig. 1C'), day-15 (data not shown) and adult testis samples (Fig. 1D'). However, protein was observed in some spermatocytes from day 10 and higher ages at a lesser intensity. The adult testis also displayed protein expression of elongated spermatids (Fig. 1D'). This staining could be attributed to the expression of tr-kit in these specific germ cell types since the antibodies used recognize an intracellular sequence in the protein (Albanesi et al. 1996). tr-kit mRNA expression was, however, not detected because the probe was designed to correspond to a region encoding the extracellular domain of the c-Kit protein.

\section{Expression of c-Kit mRNA and protein in isolated mouse spermatogonia}

Both the laminin-bound and -unbound populations were probed for the presence of $c$-Kit mRNA and protein. This separation was intended to discriminate between spermatogonia with stem cell properties (laminin bound) and those that lack stem cell properties (laminin unbound) which can be expected to have differentiated based on the transplantation studies of Shinohara et al. (1999). We predicted that the latter population would be more likely to contain $c$-Kit $\mathrm{mRNA}$ and protein, while the former would not. In situ hybridization examination of isolated spermatogonial cells ( $>95 \%$ GCNA-1 positive) showed that $c$-Kit mRNA expression was detectable in the cytoplasm of $100 \%$ of spermatogonia from both the lamininbound and -unbound populations (Fig. 2A). In contrast to the in situ hybridization data, protein detection in the cytoplasm of spermatogonia occurred in $54 \pm 2 \%$ of laminin-bound and $69 \pm 4 \%$ of the laminin-unbound cells (means \pm S.E.M.) (Fig. 2B). These experiments were performed at least three times for both mRNA and protein expression. Cells with obvious red cytoplasmic staining in the presence of primary antibody were scored as positive for C-Kit protein.

\section{Expression of c-Kit mRNA and protein in the developing rat testes}

Quantitative measurements, using real-time PCR, of mRNAs encoding $C-$ Kit in rat (1-, 2-, 3-, 5-, 7-, 9-, 15-, 20-, 30-day and adult) testes were obtained using realtime PCR on total testis RNA samples. The $c$-Kit mRNA level was highest in the rat testis on day 15 (Fig. 3A). To more precisely assess the pattern of change in mRNA levels, day-12 testis samples were included in a subsequent analysis (data not shown) with samples spanning day 9 through 26, and the day-12 sample had a higher relative level of $c$-Kit mRNA compared with either day 9 or day 15 . Thus the peak in expression of this mRNA most likely occurs between day 9 and day 15. In situ hybridization analysis of the 4-day postnatal rat testes did not show any detectable signal within gonocytes or in any other cell type (Fig. 3B). At day 13 and day 15, a weak to moderate signal for $c$-Kit mRNA was observed in the cytoplasm of spermatogonia and spermatocytes (data not shown). The signal appeared to be more intense and distinct in spermatogonia of day 19, with staining in only
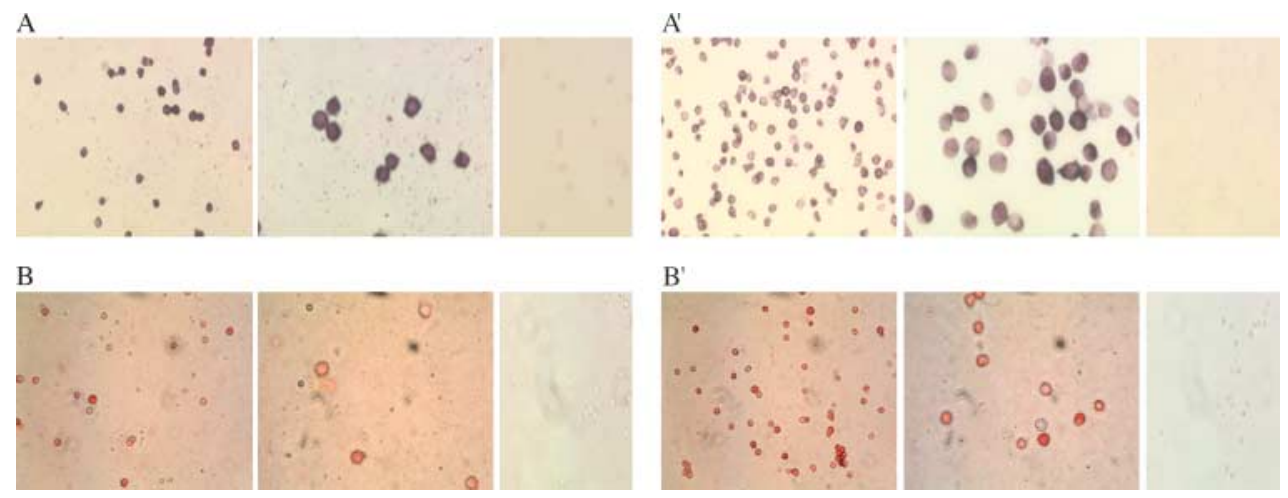

Figure 2 c-Kit expression in isolated spermatogonia from 8-day mouse testes. (A and $\mathrm{A}^{\prime}$ ) Spermatogonia in laminin-bound and -unbound populations showing $c$-Kit mRNA expression in 100\% of the cells anti-sense cRNA. (B and $B^{\prime}$ ) Spermatogonia showing c-Kit protein expression in $54 \pm 2 \%$ laminin-bound and $69 \pm 4 \%$ laminin-unbound cell populations using C-19 antibody $(n=3)$. 

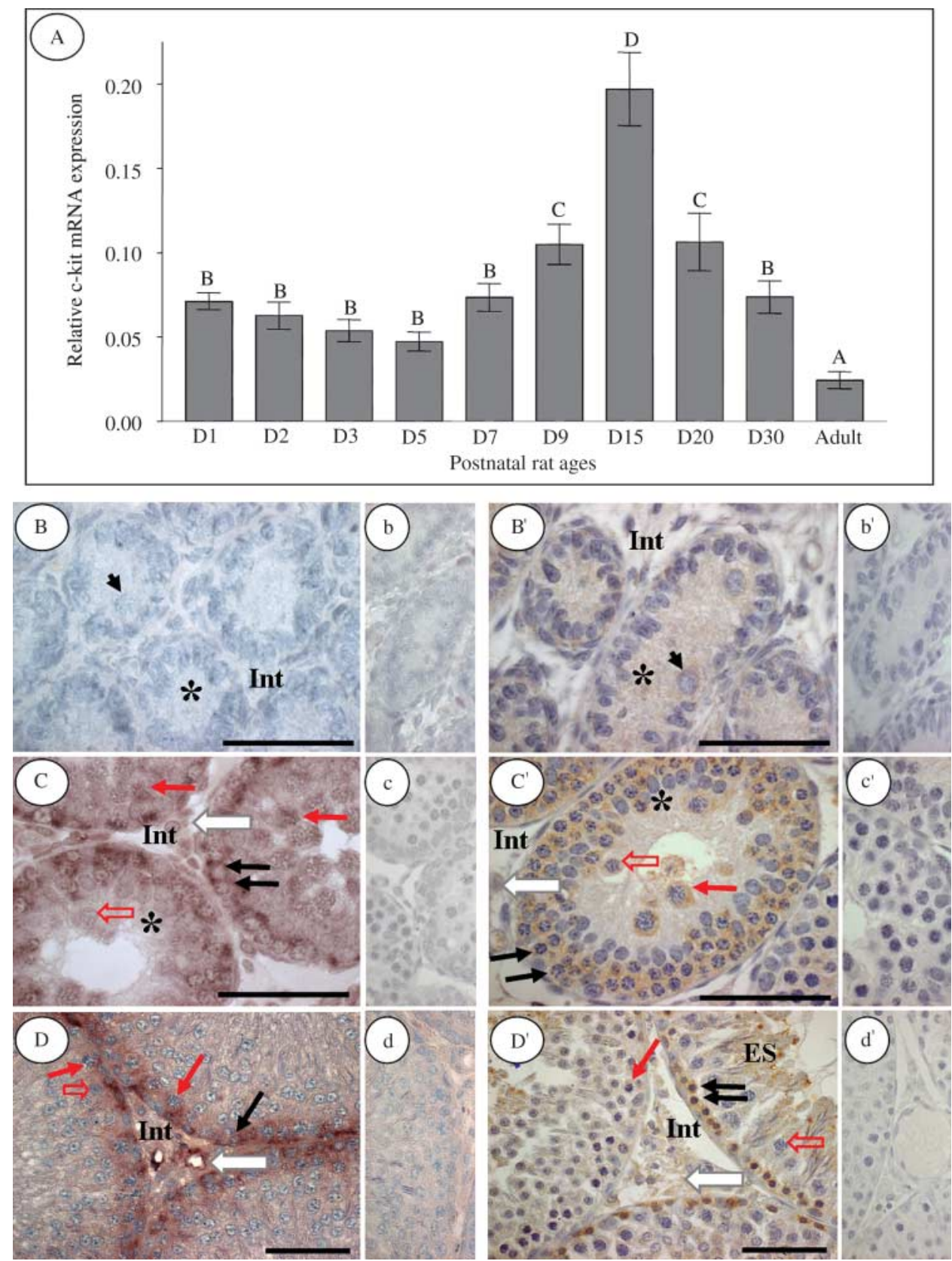

Figure 3 Juvenile and adult rat testes: $c$-Kit mRNA and protein expression profile. (A) Relative c-Kit mRNA expression profile in rat testis age series. Data were collected from three independent rat testis RNA preparations and quantified three times for each group. Results are normalized relative to GAPDH values. Error bars represent S.E.M. Different letters above the bars represent the statistical significance between ages $(P<0.05)\left(\mathrm{D}=\right.$ day after birth). (B and B) Day-4 rat testis. ( $C$ and $\left.C^{\prime}\right)$ Day-19 rat testis. ( $D$ and $\left.D^{\prime}\right)$ Adult rat testis. (B, C and D) Anti-sense cRNAs. (b, c and d) Sense cRNA controls. ( $\mathrm{B}^{\prime}, \mathrm{C}^{\prime}$ and $\left.\mathrm{D}^{\prime}\right)$ CD117 anti-c-Kit antibody. ( $\mathrm{b}^{\prime}, \mathrm{c}^{\prime}$ and $\mathrm{d}^{\prime}$ ) No primary antibody controls. Black arrowheads, gonocyte; thin black arrows, spermatogonium; red arrows, pachytene spermatocyte; open red arrows, pachytene spermatocyte with weak to no staining; asterisks, Sertoli cell cytoplasm; Int, interstitium; ES, elongating spermatid cytoplasm; white arrows, positively stained interstitial cells. Bars equal $50 \mu \mathrm{m}$.

some spermatocyte (Fig. 3C). Adult rat testes also exhibited similar staining patterns (Fig. 3D). Both day-19 and adult testes had detectable interstitial staining.

Immunohistochemical detection of c-Kit protein revealed faint staining in the cytoplasm of gonocytes of the day-4 (Fig. 3B') and day-6 rat testis (data not shown).
Since no mRNA signal was detected in gonocytes it is possible that the c-Kit protein is produced in male germ cells of the fetal testis, as previously documented (Manova \& Bachvarova 1991) and the protein remains stable within these cells for several days. A similar observation has been made for the activin $\beta A$ subunit in the fetal and 
newborn rat testis (Meehan et al. 2000). A relatively weak signal was observed in differentiating spermatogonial subtypes at day 13 (data not shown), while at days 15 (data not shown) and 19 (Fig. 3C') most of the differentiating spermatogonia had readily detectable brown cytoplasmic staining, as did some pachytene spermatocytes. In the adult testis, c-Kit protein was observed in differentiated spermatogonia, pachytene spermatocytes and elongated spermatids (Fig. 3D'). As in the case of the in situ hybridization localization of $c$-Kit mRNA, the protein signal was not evident in all pachytene spermatocytes. The antibody staining of pachytene spermatocytes was more readily detectable in the day-15 and day-19 testis sections than in those from the adult testes, giving the impression that the protein was present in more of these cells and at a higher level. Staining of a distinct intracellular vesicle was also noted within some pachytene spermatocytes. Interstitial staining was present in the day-19 and adult testes sections (Fig. 3C' and $\mathrm{D}^{\prime}$ ). Tr-kit staining in the elongating spermatids was evident in the adult testis (Fig. 3D').

\section{Irradiated adult rat testis: a comparison of $\mathrm{mRNA}$ and protein expression}

In situ hybridization analysis of irradiated rat testis samples showed that $c$-Kit mRNA was detectable in the cytoplasm of spermatogonial cells from rats that received no GNRH antagonist treatment (Fig. 4A), 1 week of treatment (Fig. 4B), 2 weeks of treatment (Fig. 4C) and 4 weeks of treatment (Fig. 4D). Staining in interstitial cells, including Leydig and endothelial cells was particularly prominent in the samples from animals treated with GNRH antagonist for 4 weeks.

In contrast to the in situ hybridization data, protein was not detected in spermatogonia in the irradiated rat samples from animals receiving no treatment (Fig. 4A'), 3 days (data not shown), 1 week (Fig. 4B') and 2 weeks (Fig. 4C') of treatment. The signal was, however, readily evident in cells with the appearance of differentiating spermatogonia that were present in the 4-week $\mathrm{GnRH}$ antagonist treatment group (Fig. 4D'). Leydig cell staining was present in all samples, in agreement with the in situ hybridization data. These data were consistently observed using two different antibodies (CD117 and C-19 (data not shown)) that were verified as recognizing c-Kit protein by Western blot. These results were identical in triplicate experiments performed using testis sections from three individual animals.

\section{Discussion}

To provide for ease of comprehension, the findings have been summarized in Fig. 5. In essence, this study has illustrated the relationship between $c$-Kit mRNA and protein expression and highlights the key developmental timepoints for the onset of differentiation of both rat and mouse germ cells during the first wave of spermatogen- esis. Published descriptions of c-Kit localization and expression do not come to a common conclusion about the expression of $c$-Kit $\mathrm{mRNA}$ and protein in pachytene spermatocytes (Manova et al. 1990, Sorrentino et al. 1991, Dym et al. 1995). In this study, both mRNA and protein expression data identified $\mathrm{c}$-Kit in pachytene spermatocytes and showed that it is undetectable in round spermatids. The functional significance of expression in pachytene spermatocytes could relate to the survival of these cells during meiosis (Yan et al. 2000). The full-length c-Kit is, therefore, present both in the cytoplasm, and presumably the plasma membrane, of differentiating spermatogonia and pachytene spermatocytes in both rat and mouse. Comparison of mRNA levels measures in the total rat and mouse testis RNA by real-time PCR analysis with the appearance of $c$-Kit mRNA within specific cell types by in situ hybridization, in both rodents, revealed that expression levels increase at time-points concordant with the appearance of differentiating spermatogonia containing this transcript (McCarrey 1993). In comparison with the spermatogonial and spermatocyte staining, there was weak to no staining in the Leydig cells, a finding which suggests that Leydig cells contribute little to the total level of $c$-Kit mRNA in the testis at all ages tested. To complete this study, we were required to undertake a comparison of two commercially available antibodies that recognize the intracellular domain of the rodent c-Kit protein, and similarities and differences in their target recognition became apparent from this analysis. Though both antibodies (CD117 and C-19) gave similar outcomes when applied to Bouin-fixed sections of rat testis, only the CD117 antibody gave a clear signal on mouse testes sections.

In our analyses of two independent systems we have also uncovered evidence that $c$-Kit mRNA can be produced in the absence of detectable protein. Examination of spermatogonia isolated from the day-8 mouse testis indicates that $c$-Kit mRNA and protein are differentially regulated. Similarly, in the case of the irradiated adult rat testis, while mRNA was observed in spermatogonia in all sample groups, both mRNA and protein was detectable only in the differentiating spermatogonia present in the 4-week $\mathrm{GnRH}$ antagonist treatment group, suggesting that undifferentiated spermatogonia express $c$-Kit mRNA but not protein. Based on these observations, we hypothesize that distinct factors regulate $c$-Kit mRNA transcription and translation. These factors are presumably part of the microenvironment of the testis.

Our examination of the irradiated rat testis model provides a clue that factors regulating c-Kit protein synthesis in the testis are influenced by its exposure to hormonal stimulation. Coupling the present data with previous observations of spermatogonial morphology in these testes, we now understand that $\mathrm{c}$-Kit protein expression occurs only when differentiating spermatogonia emerge in the testes of irradiated rats treated with the $\mathrm{GnRH}$ antagonist for 4 weeks and more (Shuttlesworth et al. 2000). In a study of $W / W^{v}$ mutant mice, which produce 

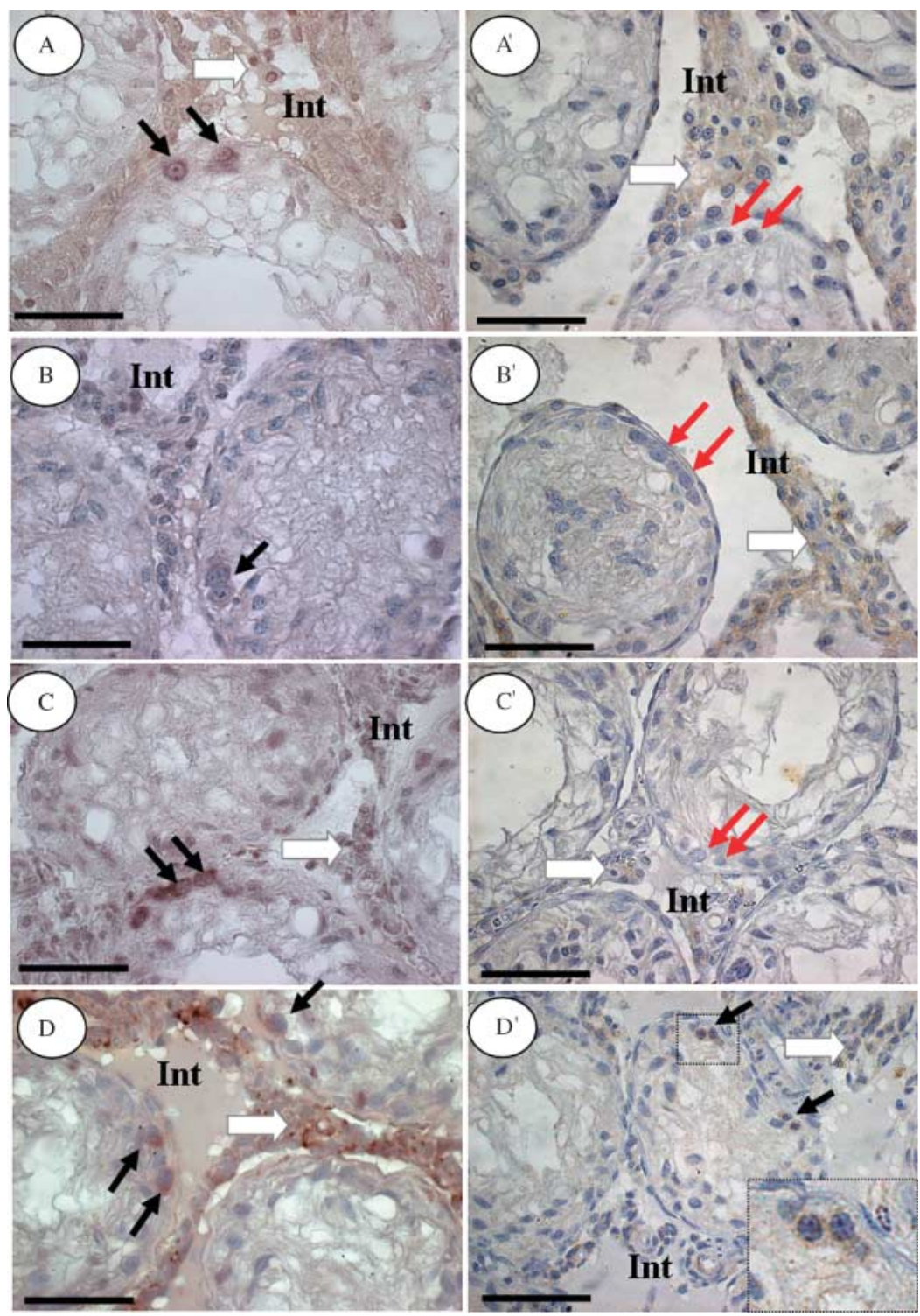

Figure 4 c-Kit mRNA and protein expression in spermatogonia of irradiated rat testes. Irradiated rat testes with: (A and $\left.\mathrm{A}^{\prime}\right)$ no GNRH antagonist treatment, $\left(B\right.$ and $\left.B^{\prime}\right)$ GnRH antagonist treatment administered for 1 week, (C and $\left.C^{\prime}\right)$ GnRH antagonist treatment for 2 weeks and (D and $\left.D^{\prime}\right)$ GnRH antagonist treatment for 4 weeks. (A, B, C and D) Anti-sense cRNA. (A', B', C' and D') Sections with CD117 antibody added. Area within dotted box in $\left(\mathrm{D}^{\prime}\right)$ is enlarged as an inset to illustrate spermatogonia with antibody binding. Black arrows, stained spermatogonium; red arrows, unstained spermatogonium; Int, interstitium; white arrows, stained interstitial cell. Bars equal $50 \mu \mathrm{m}$.

non-functional c-Kit receptor protein, spermatogonia expressing c-Kit are present in 2-week-old $W / W^{v}$ mutant mice but are absent in 10-week-old animals (Ohta et al. 2003). Administration of a GNRH antagonist for 4 weeks to reduce intratesticular testosterone in 10-week-old $W W^{v}$ mice resulted in the emergence of c-Kit-positive spermatogonia. While production of $c-$ Kit mRNA was not assessed in the latter study, it appears that reduction of the intratesticular testosterone concentration stimulates differentiation of spermatogonia in a manner independent of c-Kit function, but leading to the onset of c-Kit protein expression. Another known factor to stimulate the expression of surface c-Kit protein is BMP4, as shown by the expression of surface c-kit protein on 4-day postnatal spermatogonia after exposure to BMP4 (bone morphogenetic protein-4; Pellegrini et al. 2003). Microarray data for BMP4 expression in the irradiated rat testes indicate an elevation in this mRNA after 2 weeks of $\mathrm{GnRH}$ antagonist treatment group $(\mathrm{O} \cup$ Bolden-Tiller \& M L Meistrich, unpublished results). These data coupled with our localization studies on c-Kit expression suggest that there could be translational regulation of c-Kit by BMP4. Current studies are underway to assess BMP4 protein expression at this stage.

In conclusion, the results of our study identify the key time-points and cell types for c-Kit mRNA production in the developing rodent testis and indicate that mRNA is 

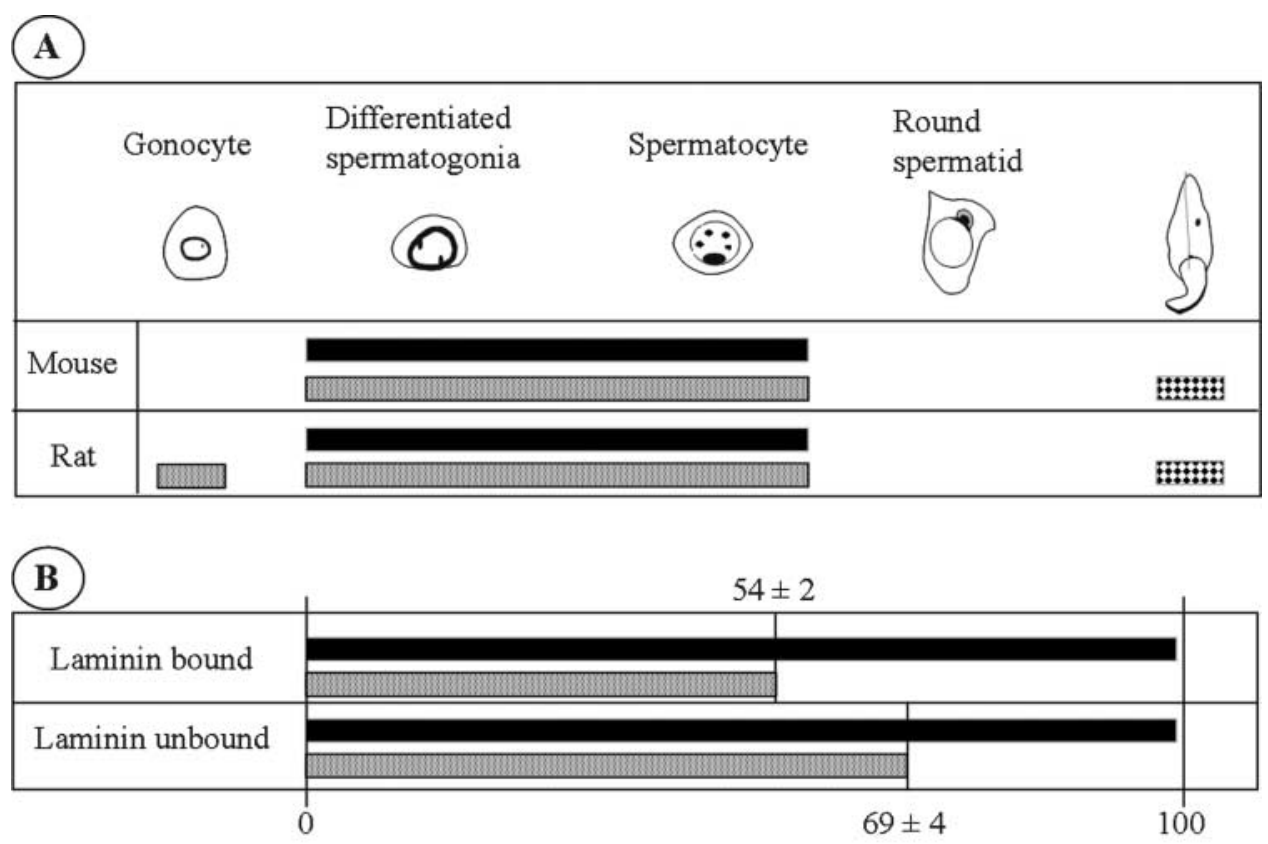

(C)

\begin{tabular}{|ccccc|}
\hline No treatment & 3 days & 1 week & 2 weeks & 4 weeks \\
\hline & & &
\end{tabular}

Figure 5 Summary of $c$-Kit mRNA and protein. (A) Normal mouse and rat testis cellular localization profile of $c$-Kit mRNA detection and protein. (B) Expression in purified spermatogonia. Numbers indicate percentage ( \pm S.D.) of cells expressing c-Kit. (C) Expression profile in irradiated rat testes. Cell types in no treatment, 3-day and 1- and 2-week groups are undifferentiated spermatogonia; differentiated spermatogonia appear in the 4-week group. Black bars, c-Kit mRNA expression; shaded bars, c-Kit protein expression; chequered bars, tr-kit protein expression.

present in the absence of detectable levels of protein. It also indicates that a spermatogonial stem cell could have c-Kit mRNA expression and exhibit regenerative capacity, while corresponding protein expression in the spermatogonia results in lesser potential for regeneration. This observation is particularly intriguing, as it provides the opportunity to design appropriate studies for analysis of the regulation of both c-Kit mRNA transcription and its translation into protein, the latter of which is a key determinant of germ cell survival, proliferation and migration.

\section{Acknowledgements}

This work has been supported by funding from the National Health and Medical Research Council of Australia (Fellowship No. 143792, Program Grant No. 143786 to K L L), National Institute of Environmental Health Sciences, USA (Grant ES-08075 to M L M) and the Australian Research Council (K L L, E A M and S D R). The authors would like to acknowledge Adrian Nañez and Gene Wilson for irradiation of the rats and preparation of the tissues from irradiated rats and Jaclyn Low for technical assistance with the spermatogonial preparations. Thanks to Dr Thomas Reissmann at ASTA Medica for sending us the centroselix. The authors declare that there is no conflict of interest that would prejudice the impartiality of this work.

\section{References}

Albanesi C, Geremia R, Giorgio M, Dolci S, Sette C \& Rossi P 1996 A cell- and developmental stage-specific promoter drives the expression of a truncated c-kit protein during mouse spermatid elongation. Development 122 1291-1302.

Arya M \& Vanha-Perttula T 1986 Comparison of lectin-staining pattern in testis and epididymis of gerbil, guinea pig, mouse, and nutria. American Journal of Anatomy 175 449-469.

Baleato RM, Aitken RJ \& Roman SD 2005 Vitamin A regulation of BMP4 expression in the male germ line. Developmental Biology $28678-90$.

Chomczynski P \& Sacchi N 1987 Single-step method of RNA isolation by acid guanidinium thiocyanate-phenol-chloroform extraction. Analytical Biochemistry 162 156-159.

Dym M, Jia MC, Dirami G, Price JM, Rabin SJ, Mocchetti I \& Ravindranath N 1995 Expression of c-kit receptor and its autophosphorylation in immature rat type A spermatogonia. Biology of Reproduction 52 8-19.

Hasthorpe S, Barbic S, Farmer PJ \& Hutson JM 1999 Neonatal mouse gonocyte proliferation assayed by an in vitro clonogenic method. Journal of Reproduction and Fertility 116 335-344.

Kangasniemi M, Huhtaniemi I \& Meistrich ML 1996 Failure of spermatogenesis to recover despite the presence of spermatogonia in the irradiated LBNF1 rat. Biology of Reproduction 54 1200-1208. 
Loveland KL \& Schlatt S 1997 Stem cell factor and c-kit in the mammalian testis: lessons originating from Mother Nature's gene knockouts. Journal of Endocrinology 153 337-344.

McCarrey JR 1993 Development of the germ cell. In Cell and Molecular Biology of the Testis, pp 58-89. Eds C Desjardins \& LL Ewing. Oxford: Oxford University Press, Inc.

Manova K, Nocka K, Besmer P \& Bachvarova RF 1990 Gonadal expression of c-kit encoded at the W locus of the mouse. Development 110 1057-1069.

Manova K \& Bachvarova RF 1991 Expression of c-kit encoded at the W locus of mice in developing embryonic germ cells and presumptive melanoblasts. Developmental Biology 146 312-324.

Mauduit C, Hamamah S \& Benahmed M 1999 Stem cell factor/c-kit system in spermatogenesis. Human Reproduction Update 5 535-545.

Meehan T, Schlatt S, O'Bryan MK, de Kretser DM \& Loveland KL 2000 Regulation of germ cell and Sertoli cell development by activin, follistatin, and FSH. Developmental Biology 220 225-237.

Nocka K, Majumder S, Chabot B, Ray P, Cervone M, Bernstein A \& Besmer P 1989 Expression of c-kit gene products in known cellular targets of $\mathrm{W}$ mutations in normal and $\mathrm{W}$ mutant mice, evidence for an impaired c-kit kinase in mutant mice. Genes and Development 3 816-826.

Ohbo K, Yoshida S, Ohmura M, Ohneda O, Ogawa T, Tsuchiya H, Kuwana T, Kehler J, Abe K, Scholer HR \& Suda T 2003 Identification and characterization of stem cells in prepubertal spermatogenesis in mice. Developmental Biology 258 209-225.

Ohta H, Tohda A \& Nishimune Y 2003 Proliferation and differentiation of spermatogonial stem cells in the $\mathrm{w} / \mathrm{wv}$ mutant mouse testis. Biology of Reproduction 69 1815-1821.

Orth JM, Jester WF Jr \& Qiu J 1996 Gonocytes in testes of neonatal rats express the c-kit gene. Molecular Reproduction and Development 45 123-131.

Orth JM, Qiu J, Jester WF Jr \& Pilder S 1997 Expression of c-kit gene is critical for migration of neonatal rat gonocytes in vitro. Biology of Reproduciton 57 676-683.

Packer AI, Besmer P \& Bachvarova RF 1995 Kit ligand mediates survival of type A spermatogonia and dividing spermatocytes in postnatal mouse testes. Molecular Reproduction and Development 42 303-310.

Pellegrini M, Grimaldi P, Rossi P, Geremia R \& Dolci S 2003 Developmental expression of BMP4/ALK3/SMAD5 signaling pathway in the mouse testis: a potential role of BMP4 in spermatogonia differentiation. Journal of Cell Science 116 3363-3372.

Qiu FH, Ray P, Brown K, Barker PE, Jhanwar S, Ruddle FH \& Besmer P 1988 Primary structure of c-kit: relationship with the CSF1/PDGF receptor kinase family - oncogenic activation of v-kit involves deletion of extracellular domain and $\mathrm{C}$ terminus. $E M B O$ Journal 7 1003-1011.

de Rooij DG \& Grootegoed JA 1998 Spermatogonial stem cells. Current Opinion in Cell Biology 10 694-701.

Rothschild G, Sottas CM, Kissel H, Agosti V, Manova K, Hardy MP \& Besmer P 2003 A role for kit receptor signaling in Leydig cell steroidogenesis. Biology of Reproduction 69 925-932.

Schrans-Stassen BH, van de Kant HJ, de Rooij DG \& van Pelt AM 1999 Differential expression of c-kit in mouse undifferentiated and differentiating type A spermatogonia. Endocrinology $\mathbf{1 4 0}$ 5894-5900.

Shinohara T, Avarbock MR \& Brinster RL 1999 beta1- and alpha6integrin are surface markers on mouse spermatogonial stem cells. PNAS 96 5504-5509.

Shuttlesworth GA, de Rooij DG, Huhtaniemi I, Reissmann T, Russell LD, Shetty G, Wilson G \& Meistrich ML 2000 Enhancement of A spermatogonial proliferation and differentiation in irradiated rats by gonadotropin-releasing hormone antagonist administration. Endocrinology $14137-49$.

Sorrentino V, Giorgi M, Geremia R, Besmer P \& Rossi P 1991 Expression of the c-kit proto-oncogene in the murine male germ cells. Oncogene 6 149-151.

Vincent S, Segretain D, Nishikawa S, Nishikawa SI, Sage J, Cuzin F \& Rassoulzadegan M 1998 Stage-specific expression of the Kit receptor and its ligand $(\mathrm{KL})$ during male gametogenesis in the mouse: a Kit-KL interaction critical for meiosis. Development 125 4585-4593.

Wang \& Enders 1996 Expression of a specific mouse germ cell nuclear antigen (GCNA1) by early embryonic testicular teratoma cells in 129/Sv-Sl/+ mice. Cancer Letters $10031-36$.

Yan W, Suominen J \& Toppari J 2000 Stem cell factor protects germ cells from apoptosis in vitro. Journal of Cell Science 113 161-168.

Yoshinaga K, Nishikawa S, Ogawa M, Hayashi S, Kunisada T, Fujimoto T \& Nishikawa S 1991 Role of c-kit in mouse spermatogenesis: identification of spermatogonia as a specific site of c-kit expression and function. Development 113 689-699.

Zama AM, Hudson FP \& Bedell MA 2005 Analysis of hypomorphic kitlsl mutants suggests different requirements for KITL in proliferation and migration of mouse primordial germ cells. Biology of Reproduction 73 639-647 Epub 2005 May 25.

Received 16 September 2005

First decision 25 October 2005

Revised manuscript received 14 November 2005

Accepted 22 November 2005 